\title{
Narrative review of the impact of clinical psychiatry attachments on attitudes to psychiatry ${ }^{\dagger}$
}

\author{
Henna Qureshi, ${ }^{1}$ Stuart Carney, ${ }^{2}$ Amy Iversen ${ }^{3}$
}

The Psychiatrist (2013), 37, 104-110, doi: 10.1192/pb.bp.111.037820

'King's College Hospital, London, UK; ${ }^{2}$ UK Foundation Programme Office, Cardiff Bay, UK; ${ }^{3}$ King's College London, UK

Correspondence to Henna Qureshi (henna.qureshi@doctors.org.uk)

First received 13 Nov 2011, final revision 24 Oct 2012, accepted 31 Oct 2012

\begin{abstract}
Aims and method Psychiatry in the UK has long-standing issues in recruiting UK-trained doctors. A key potential influence on interest in psychiatry during medical school is the clinical attachment. This narrative review investigates how the clinical experience of psychiatry affects medical students' attitudes towards the specialty.

Results We identified 107 studies, of which 46 were included. They showed that clinical attachments in psychiatry did result in more positive attitudes towards the specialty and increased career interest. There was inconsistent evidence on whether interest was maintained, with some studies indicating that the increase is transient. Factors which may influence attitudes include attachment setting, duration and student demographics.
\end{abstract}

Clinical implications The results suggest a need to actively maintain interest in psychiatry throughout medical school. Research with long-term follow-up and evaluation of schemes to maintain students' interest is needed.

Declaration of interest None.
Recruitment problems in psychiatry have been longstanding; between 1974 and 2000 the percentage of UK medical graduates choosing a career in psychiatry has remained around $4 \%{ }^{1,2}$ There is growing concern over the future of British psychiatry. It had the lowest number of applicants per training place in 2010 , and historically the highest proportion of overseas applicants to specialty training places $(86 \%)$ of all medical specialties. ${ }^{3}$ Although international medical graduates are vital to psychiatric services, fewer pass MRCPsych examinations than UK graduates. ${ }^{4,5}$ There are also concerns about communication and cultural understanding among some international medical graduates, ${ }^{6}$ qualities of particular importance to psychiatry. The widespread feeling is that more UK graduates are needed in the specialty.

\section{Medical students' misgivings about psychiatry}

The intention to pursue psychiatry among sixth-form students is high at $12.4 \%{ }^{7}$ yet on entry to medical school attitudes towards psychiatry are less favourable than attitudes towards other specialties, perhaps because of medical school selection criteria. ${ }^{2,8}$ Some medical students

This is one of a series of papers on recruitment in psychiatry. See also Archdall et al (pp. 21-24), Oakley et al (pp. 25-29) and Kelley et al (pp. 30-32) published in January and Greening et al (pp. 65-71) published in February. feel psychiatry is not scientific enough (35.5\%) and does not make use of their medical skills (17.2\%). ${ }^{9}$ They also believe psychiatry has stressful working conditions, ${ }^{2}$ ineffective treatments $(24.1 \%)$ and that patients do not improve. ${ }^{9}$ Furthermore, they hold negative views of psychiatrists themselves, believing they are 'second-rate' doctors (9.2\%) or are emotionally unstable $(4 \%) .{ }^{9}$ Those medical students with an interest in psychiatry face stigma from other students and teachers. ${ }^{10}$ Indeed, 'bad-mouthing' against psychiatry from doctors is widely reported, starting from the first year of medical school. ${ }^{11-13}$ This is worsened by the relative absence of psychiatrists at medical school, owing partly to the separation of mental health trusts from acute trusts and to psychiatrists having a limited role as medical educators. This is reflected by the fact that psychological principles have only recently been included in the UK medical curriculum. ${ }^{14}$

A key potential influence on medical student interest in psychiatry is the clinical attachment. ${ }^{11,15,16}$ Several reviews have briefly addressed this area, ${ }^{11,15,17,18}$ but they lack a systematic methodology. They suggest that the clinical attachment is an important factor in recruitment to psychiatry and that it may positively affect attitudes to psychiatry, but that this may be transient. The recent World Psychiatry Association guidance summarises this issue. ${ }^{19}$ We therefore carried out a narrataive literature review to assess in detail how clinical exposure to psychiatry affects medical students' attitudes towards it. 


\section{Method}

In March 2011, we searched BIOSIS Previews (1969-2011), EMBASE (1980-2011), MEDLINE (1950-2011), PsycINFO (1806-2011), Scopus (1960-2011) and Web of Science (1899-2011) databases for the following free-text words in the title and abstract: undergraduate, medical students, medical school; attitudes, perception; psychiatry, psychology; change, cohort. Additional search methods included hand-searching bibliographies of retrieved publications, citations of retrieved publications and Google Scholar. We excluded studies that were not in English, did not include exposure to people with mental illness, carried out an intervention, were not from the UK, Europe, North America, Australia or New Zealand, or were from before 1990 , because of the subsequent changes in psychiatry and medical education. However, we considered studies published after 1980 if they included long-term follow-up, as this was rarely undertaken.

The data were synthesised into four evidence levels (Table 1), as taken from de Croon et al. ${ }^{20}$

\section{Results}

In total, 107 publications were identified, of which 61 studies were excluded. Therefore, this review is based on 46 publications, which report 41 studies; 31 studies explored attitude change following attachments in general psychiatry. Another study ${ }^{21}$ did not specify direction of attitude change so is not included in the analysis. There were 8 crosssectional studies, 22 longitudinal studies and 1 study using both designs. The Studies used a variety of tools, including the Attitudes to Mental Illness Questionnaire, ${ }^{22}$ the Attitudes Towards Psychiatry questionnaire (ATP-30), ${ }^{23}$ the Child and Adolescent Psychiatry Experiences Questionnaire, ${ }^{24}$ the Libertarian Mental Health Ideology Scale, ${ }^{25}$ the Opinions About Mental Illness questionnaire, ${ }^{26,27}$ the Specific Attitudes towards Psychiatry questionnaire, ${ }^{28}$ and the Derogatis' Symptom Checklist. ${ }^{29}$ Other studies created their own tools. Of the remaining included studies, five explored attitude change following attachments in subspecialties and four focused on the impact of curriculum or setting on attitudes.

Overall, the evidence suggests that attitudes to psychiatry significantly improved after clinical attachments, although the evidence level is inconsistent (positive: 20; no change: 11; negative: 1 ; note that this includes two results from Kuhnigk et $a l,{ }^{30}$ as this study had a cross-sectional and a longitudinal group). Taken alone, cross-sectional studies surveying attitudes towards general psychiatry across medical school years provided inconsistent evidence (positive: 4; no change: 4; negative: 1). In contrast, longitudinal studies, where attitudes were measured before and after attachments, provided strong evidence of a positive change following clinical exposure (positive: 16; no change: 7 ; negative: 0 ).

Nine of the longitudinal studies used the ATP-30, a 30-item questionnaire exploring attitudes towards people with psychiatric illness, psychiatric illness itself, treatment, psychiatric institutions and psychiatrists, teaching, knowledge and career choice. ${ }^{23}$ The ATP-30 contains a mixture of positively and negatively worded statements rated on a five-point Likert scale. Higher scores indicate more favourable attitudes, with 150 being very positive, 90 being neutral and 30 being very negative. The results are presented in Fig. 1,,$^{23,30-36}$ except for one study which did not report total scores. ${ }^{37}$

Of all the studies included, only eight had a long-term follow-up, varying between 3 months and 10 years. Seven found positive attitude change post-attachment, but provided inconsistent evidence on whether this change was maintained (maintained: 3; mixed: 1; not maintained: 3). Even where positive attitude change was maintained, some decay was reported. ${ }^{34}$ Moreover, in some studies attitudes declined to below pre-attachment levels. ${ }^{33,38}$ There has been no investigation of whether transient attitude improvement is seen following other specialty attachments. $^{33}$

The relationship between clinical attachments, attitudes to psychiatry and subsequent career interest was explored by 14 studies. They provided strong evidence of increased career interest post-attachment (increased: 10 studies; no change: 3 studies; decreased: 1 study). This increased career interest appears to be mediated by a change in attitude towards the specialty; the only studies not reporting increased career interest post-attachment were those in which students showed no positive change in attitudes. One study compared attitudes with actual career decisions, finding that the strongest predictor of actual career choice was post-attachment attitude. ${ }^{39}$ Interestingly,

\begin{tabular}{ll} 
Table 1 Criteria for evidence levels \\
Evidence level & Criteria \\
\hline 1 No evidence & $\leqslant 1$ study available \\
\hline 2 Weak evidence & $\begin{array}{l}2 \text { studies available that find a significant association in the same direction or } 3 \text { studies available, } \\
\text { of which } 2 \text { find a significant association in the same direction and the third study finds no } \\
\text { significant association }\end{array}$ \\
\hline 3 Strong evidence & $\begin{array}{l}3 \text { studies available that find an association in the same direction or }>4 \text { studies available, of which } \\
>66 \% \text { find a significant association in the same direction and no more than } 25 \% \text { find an opposite } \\
\text { association }\end{array}$ \\
\hline 4 Inconsistent evidence & Remaining cases \\
\hline No association & $>4$ studies, of which $>75 \%$ find no association \\
Weak evidence & $>4$ studies, of which $>85 \%$ find no association
\end{tabular}






Fig 1 Results of longitudinal studies which used the 30-item Attitudes Towards Psychiatry questionnaire (ATP-30). Follow-up scores are included where a follow-up was conducted. a. Results included three samples; the lowest $P$-value is given here. b. Results included two samples; the lowest $P$-value is given here.

two studies suggested the attachment had a significant influence on the decision not to pursue a career in psychiatry. ${ }^{31,40}$ For example, after students completed their attachment, Creed \& Goldberg ${ }^{31}$ investigated how likely they were to pursue psychiatry: $11 \%$ were 'less likely', $23 \%$ were 'unchanged', $55 \%$ were 'somewhat more likely' and $11 \%$ were 'much more likely'.

Only three studies contained a longer-term follow-up on career interest. Career interest was maintained in one study at $2-3$ years $^{41}$ and not maintained in the remaining two studies at 2 years ${ }^{38}$ and 5 years. ${ }^{31}$

\section{Attitudes and features of the attachment}

Three studies explored the effect of attachment setting on attitudes, providing inconsistent evidence. Bobo et $a l^{42}$ found that the setting (including an acute in-patient ward, a hospital-based consultation-liaison service, and an out-patient mental healthcare clinic) made no difference to attitudes. In contrast, Clardy et $a l^{39}$ found there to be increased career interest in out-patient attachments compared with the emergency room, children's hospital, in-patient or consultant/liaison settings, but reported that this did not influence actual career choice. Walters et $a l^{43}$ found that students valued primary care-based teaching highly compared with teaching in hospital settings. Benefits included seeing the milder spectrum of mental illness and less stereotyping of patients with severe mental illness. In studies where attachments consisted of a block of a subspecialty of psychiatry, there was evidence of positive attitude change after attachments in child and adolescent psychiatry (weak evidence) ${ }^{24,44}$ and addictions psychiatry (strong evidence). ${ }^{45-47}$

Oakley \& Oyebode ${ }^{48}$ examined attitudes to the psychiatry curriculum. Students favoured more integration, with the overall curriculum and teaching focused on scenarios they expected to encounter in their early employment, such as suicide risk assessment. Two studies explored the impact on attitudes of a problem-based learning compared with a traditional curriculum. Both found no difference, providing weak evidence that curriculum design within psychiatry does not affect attitudes. ${ }^{22,41}$

Attachment length varied from 2 to 16 weeks across studies in this review. Although Singh et $a l^{22}$ primarily looked at the impact of curriculum on attitudes, theirs was the only study to examine the impact of attachment length. They found no clear association between attitudes and duration. However, given that the primary difference was curriculum rather than duration, this evidence is limited.

Studies examining experiences during the attachment found an association between increasing positive attitudes and: positive course ratings; ${ }^{30}$ involvement in in-patient care; seeing good response to treatment; and encouragement from consultants during the attachment. ${ }^{34}$ This indicates that experiences of teaching can have a positive impact on students regardless of pre-attachment attitudes. ${ }^{34}$ On the other hand, poor teaching and unwelcoming staff seem to contribute to negative attitudes. ${ }^{49}$ Interestingly, there is strong evidence that better academic performance on a psychiatry attachment does not correlate with increased positive attitudes to the specialty (positive correlation: 2 studies; no correlation: 5 studies).

\section{Sociodemographics}

Sociodemographic variables were examined. One study found no difference in attitudes to psychiatry between graduate and undergraduate students. ${ }^{50}$ Those who had studied humanities were also no more likely to have positive attitudes than those who had studied sciences. ${ }^{30}$ Although there is insufficient evidence to rate the strength of findings, support is provided by Lambert et al's large UK survey, which found that the medical career choices of graduate entrants were similar to those of non-graduates. ${ }^{51}$

Sixteen studies explored the association between gender and attitudes to psychiatry, providing inconsistent evidence (females more positive: 5 studies; no correlation: 11 studies). Two studies suggested career interest was greater in males, ${ }^{32,34}$ although the evidence level is weak.

Ethnicity and nationality have also been addressed. One study reported more negative attitudes in students from outside the European Union, but it is limited by a small sample. ${ }^{35}$ Korszun et al found Chinese and South Asian students had more negative attitudes towards patients with long-standing delusions and hallucinations than White British students. ${ }^{50}$

Finally, prior personal experience of mental illness was explored. There is strong evidence that experience of mental illness is associated with more positive attitudes among 
medical students (positive: 6 studies; no correlation: 2 studies).

\section{Discussion}

This review suggests that psychiatry attachments can positively influence attitudes and career interest. Existing research shows this may be transient; however, long-term follow-up is limited. The results reflect psychiatry's low popularity among medical students ${ }^{52}$ and applicants for training posts. ${ }^{3}$ Students may benefit from out-patient and primary care settings and exposure to subspecialties, rather than general adult psychiatry in in-patient settings. Sociodemographic factors, including previous degrees and gender, appear to have little association with positive attitudes. Students trained outside the European Union may have less favourable attitudes.

\section{Attachment features}

The role of attachment setting is uncertain. Although it is reported that students find out-patient attachments more useful and rewarding, ${ }^{53}$ this may not affect their career choice. ${ }^{39}$ In-patient attachments may reinforce negative attitudes, for example that psychiatric illnesses are untreatable. ${ }^{54}$ However, students benefit from continuity, closer supervision and demonstration of obvious psychopathology. ${ }^{20}$ In addition, integrating psychiatry teaching with primary care has been advocated. ${ }^{43,48}$

Features of the attachment, such as duration, seem less important than its quality. ${ }^{55}$ Indeed, a large American survey found no association between duration of attachment and psychiatry recruitment. ${ }^{56}$ The weak evidence of positive attitude change after a child and adolescent psychiatry placement ${ }^{24,44}$ and strong evidence for change after addictions psychiatry ${ }^{46,47,57}$ highlight the importance of exposing students to subspecialties. This increases awareness of the diversity within psychiatry. ${ }^{54}$

There was strong evidence that greater academic performance in psychiatry following an attachment does not correlate with improved attitudes. Fabrega ${ }^{58}$ therefore argues that improving students' knowledge is not the priority in psychiatry recruitment. Rather, the focus should be on helping students see psychiatric patients in a more human and positive light.

\section{Sociodemographic factors}

The review suggests that personal experience of mental illness is associated with more positive attitudes among medical students. The same is well demonstrated for lay populations. $^{59}$ Despite the widely held assertion that females have more positive attitudes towards psychiatry than males, ${ }^{60}$ gender correlations were inconsistent. Given that two-thirds of medical students are now female, there is a need for prominent female role models within psychiatry, as well as in other specialties. ${ }^{61}$

Perhaps not surprisingly, results suggest attitudes vary with ethnicity. ${ }^{35,50}$ Though under-researched, several factors identified in the general population may be relevant to medicine. ${ }^{62,63}$ Cinnirella \& Loewenthal's UK qualitative study highlights religious factors. ${ }^{62}$ For example, Indian Hindus cited 'bad spirits' as a cause of mental illness, whereas among Pakistani Muslims lack of faith was believed to be a causal factor in depression. Fear of stigma from the community was widespread among Orthodox Jewish, Pakistani Muslim and African-Caribbean Christian participants. $^{62}$

\section{Wider context}

It is important to consider these results in a wider context. Overall, medical student attitudes towards psychiatry have become more positive over the past 50 years, ${ }^{64}$ mirroring changes in the general population's attitudes towards mental illness. ${ }^{65}$ Therefore attitudes alone do not explain psychiatry's current recruitment problem. A trend observed for decades is a decline during medical school in idealism, empathy and attitudes towards patient-centred care. ${ }^{66-69}$ One could postulate there is something innate within medical school education which erodes the characteristics needed in future psychiatrists. This, combined with the negative attitude of non-psychiatrists to the specialty, may partly explain the disparity between interest in psychiatry expressed by sixth-form students when compared with medical students. ${ }^{7}$ Alternatively, a loss of idealism and empathy experienced at medical school may reflect a loss of naivety and increased realism, which are important survival mechanisms for the future doctor. ${ }^{66}$

Although recruitment is particularly topical and a contemporary concern for the specialty, it is important to remember that most medical students will not go into psychiatry, but are likely to encounter psychiatric issues in many fields of medicine. ${ }^{70}$ Given that even common mental illnesses such as depression have low levels of recognition among non-psychiatric physicians, ${ }^{71}$ it is important to strive to improve the attitudes of all medical students towards psychiatry, regardless of their eventual career choice.

\section{Limitations of the literature base}

Existing studies are limited by a number of methodological issues. First, few studies examined attitude change in control groups. One study by Arkar \& $\mathrm{Eker}^{72}$ found that attitudes to psychiatry also improved in students undertaking an ophthalmology attachment, bringing into question the significance of findings from studies without controls. However, controls in the study were not randomly selected but were medical students and attitudes were measured at different times, limiting reliability. Additionally, there were two other studies containing control groups in which there were no positive attitude changes in controls. ${ }^{23,73}$

Second, social desirability bias limits the findings. This was assessed in two studies using the Marlowe-Crowne Social Desirability Scale and found not to correlate with attitudes. ${ }^{35,41,74}$ Although many studies tried to limit the impact of this bias by emphasising that responses would not affect assessments and were anonymous, it is still likely be active.

Third, the studies used a variety of different methods, limiting comparability. In particular, few studies used a longitudinal design or included long-term follow-up of attitudes. 
Fourth, not all studies utilised widely used, psychometrically tested instruments. Several used the ATP-30 questionnaire, which has good validity and reliability, but perhaps needs updating to reflect changed perceptions and scientific advances in psychiatry since the 1980s. Moreover, questionnaire-based research is intrinsically limited. Improved attitudes after attachments may simply reflect increased knowledge, which does not necessarily mean reduced stigma. Qualitative research has revealed several areas discouraging medical students from pursuing psychiatry: the belief that psychiatry is not real medicine; feeling they lack necessary skills such as empathy; ${ }^{75}$ and fearing the impact of stressful emotional reactions during the attachment. ${ }^{76}$ Cutler et $a l^{77}$ highlight the need to acknowledge and discuss stressful student experiences, which would improve the attachment experience and may help recruitment.

\section{Limitations of the review}

This review has several limitations. Only English language publications were included. Publication bias may also be a factor, perhaps resulting in studies showing negative or no change in attitudes not being published, or being published outside the peer-review process. We included studies dating back to 1982, despite the substantial changes to psychiatry and psychiatric education. This was necessary given the scarcity of studies with long-term follow-up. The inclusion of studies from numerous countries (Australia, Canada, Denmark, Finland, Germany, Greece, Hungary, Ireland, Portugal, Slovenia, Spain, Turkey, the UK and the USA) limits comparability. Although beyond the scope of this review, studies from low- and middle-income countries may add valuable information, since recruiting psychiatrists is a global problem. Such studies may also provide insight into our own workforce, given the large numbers of international medical graduates entering psychiatry in the UK.

\section{Implications for future research and practice}

This review has found that medical students are not 'allergic' to psychiatry; the clinical attachment in psychiatry is an excellent opportunity to recruit young minds to the specialty. However, there is an urgent need to actively maintain student interest in psychiatry throughout medical school. How best to do this requires further research. Methods might include summer schools, special study modules, prizes, electives, intercalated degrees, opportunities for mentorship and integrating psychiatry teaching into the wider curriculum.

The impact of variation in the nature and length of attachments needs further research. This is particularly important with the reduction in emphasis on secondary and tertiary care settings; in the future, most psychiatry will be taking place in primary care and the impact of such a setting on career choice and attitudes to the specialty needs to be determined.

Further research with long-term follow-up is needed to expand the evidence base. However, conducting cohort studies from the point of entry to medical school until specialty choice may be time- or cost-prohibitive.
Finally, there is a need for the development of a new or updated measure of student attitudes towards psychiatry. Qualitative research may be beneficial to the development of such a tool and to further exploration of the reasons behind lack of career interest in medical students.

\section{About the authors}

Dr Henna Qureshi is a Foundation Year 2 doctor at King's College Hospital, London. Dr Stuart Carney is Deputy National Director of the UK Foundation Programme. Dr Amy Iversen is an Honorary Consultant Liaison Psychiatrist at King's College Hospital and a Senior Clinical Lecturer in Academic Psychiatry at the Institute of Psychiatry, London.

\section{References}

1 Goldacre MJ, Turner G, Fazel S, Lambert T. Career choices for psychiatry: national surveys of graduates of 1974-2000 from UK medical schools. Br J Psychiatry 2005; 186: 158-64.

2 Brockington IF, Mumford DB. Recruitment into psychiatry. Br J Psychiatry 2002; 180: 307-12.

3 Fazel S, Ebmeier KP. Specialty choice in UK junior doctors: is psychiatry the least popular specialty for UK and international medical graduates? BMC Med Educ 2009; 9: 77.

4 Brown N, Vassilas CA, Oakley C. Recruiting psychiatrists - a Sisyphean task? Psychiatr Bull 2009; 33: 390-2.

5 Bateman A. MRCPsych Examinations Cumulative Results 2008-2010. Royal College of Psychiatrists, 2011.

6 Slowther A, Hundt GL, Taylor R, Purkis J. Non UK Qualified Doctors and Good Medical Practice: The Experience of Working within a Different Professional Framework (The Warwick Report). General Medical Council, 2009.

7 Maidment R, Livingston G, Katona M, Whitaker E, Katona C. Carry on shrinking: career intentions and attitudes to psychiatry of prospective medical students. Psychiatr Bull 2003; 27: 30-2.

8 Feifel D, Moutier CY, Swerdlow NR. Attitudes toward psychiatry as a prospective career among students entering medical school. Am J Psychiatry 1999; 156: 1397-402.

9 Scott J. What puts medical students off psychiatry? Psychiatr Bull 1986; 10: 98-100.

10 Mehta N, Kassam A, Leese M, Butler G, Thornicroft G. Public attitudes towards people with mental illness in England and Scotland, 19942003. Br J Psychiatry 2009; 194: 278-84.

11 Eagles JM, Wilson S, Murdoch JM, Brown T. What impact do undergraduate experiences have upon recruitment into psychiatry? Psychiatr Bull 2007; 31: 70-2.

12 Hunt DD, Scott C, Zhong S, Goldstein E. Frequency and effect of negative comments ('Badmouthing') on medical students' career choices. Acad Med 1996; 71: 665-9.

13 Holmes D, Tumiel-Berhalter LM, Zayas LE, Watkins R. 'Bashing' of medical specialties: Students' experiences and recommendations. Fam Med 2008; 40: 400-6.

14 General Medical Council. Tomorrow's Doctors: Outcomes and Standards for Undergraduate Medical Education. GMC, 2009.

15 Sierles FS, Taylor MA. Decline of U.S. medical student career choice of psychiatry and what to do about it. Am J Psychiatry 1995; 152: 1416-26.

16 Dein K, Livingston G, Bench C. 'Why did I become a psychiatrist?': survey of consultant psychiatrists. Psychiatr Bull 2007; 31: 227-30.

17 Kelly B, Raphael B, Byrne G. The evaluation of teaching in undergraduate psychiatric education: students' attitudes to psychiatry and the evaluation of clinical competency. Med Teach 1991; 13: 77-87.

18 Balon R. Does a clerkship in psychiatry affect medical students' attitudes toward psychiatry? Acad Psychiatr 2008; 32: 73-5. 
19 Sartorius N, Gaebel W, Cleveland HR, Stuart H, Akiyama T, ArboledaFlorez J, et al. WPA guidance on how to combat stigmatization of psychiatry and psychiatrists. World Psychiatry 2010; 9: 131-44.

20 de Croon EM, Sluiter JK, Nijssen TF, Dijkmans BA, Lankhorst GJ, FringsDresen $\mathrm{MH}$. Predictive factors of work disability in rheumatoid arthritis: a systematic literature review. Ann Rheum Dis 2004; 63: 1362-7.

21 Zalar B, Strbad M, Åvab V. Psychiatric education: does it affect stigma? Acad Psychiatr 2007; 31: 245-6.

22 Singh SP, Baxter $\mathrm{H}$, Standen $\mathrm{P}$, Duggan $\mathrm{C}$. Changing the attitudes of 'tomorrow's doctors' towards mental illness and psychiatry: a comparison of two teaching methods. Med Educ 1998; 32: 115-20.

23 Burra P, Kalin R, Leichner P. The ATP 30 - a scale for measuring medical students' attitudes to psychiatry. Med Educ 1982; 16: 31-8.

24 Malloy E, Hollar D, Lindsey B. Increasing interest in child and adolescent psychiatry in the third-year clerkship: results from a post-clerkship survey. Acad Psychiatry 2008; 32: 350-6.

25 Nevid JS, Morrison J. Attitudes toward mental illness: the construction of the Libertarian Mental Health Ideology Scale. J Humanist Psychol 1980; 20: 71-85.

26 Cohen J, Struening EL. Opinions about mental illness in personnel of two large mental hospitals. J Abnorm Soc Psychol 1962; 64: 349-60.

27 Struening EL, Cohen J. Factorial invariance and other psychometric characteristics of five opinions about mental illness factors. Educ Psychol Meas 1963; 23: 289-98.

28 Wilkinson DG, Greer S, Toone BK. Medical students' attitudes to psychiatry. Psychol Med 1983; 13: 185-92.

29 Derogatis LR. SCL-90-R: Administration, Scoring and Procedures Manual for the Revised Version and Other Instruments of the Psychopathology Rating Series. School of Medicine, Johns Hopkins University, 1977.

30 Kuhnigk O, Strebel B, Schilauske J, Jueptner M. Attitudes of medical students towards psychiatry. Adv Health Sci Edu 2007; 12: 87-101.

31 Creed F, Goldberg D. Students attitudes towards psychiatry. Med Educ 1987; 21: 227-34.

32 Sloan D, Browne S, Meagher D, Lane A, Larkin C, Casey P, et al. Attitudes toward psychiatry among Irish final year medical students. Eur Psychiatry 1996; 11: 407-11.

33 Baxter H, Singh SP, Standen P, Duggan C. The attitudes of 'tomorrow's doctors' towards mental illness and psychiatry: changes during the final undergraduate year. Med Educ 2001; 35: 381-3.

34 Maidment R, Livingston G, Katona C, McParland M, Noble L. Change in attitudes to psychiatry and intention to pursue psychiatry as a career in newly qualified doctors: a follow-up of two cohorts of medical students. Med Teach 2004; 26: 565-9.

35 Glynn S, Reilly M, Avalos G, Mannion L, Carney PA. Attitudinal change toward psychiatry during undergraduate medical training in Ireland. Irish J Psychol Med 2006; 23: 131-3.

36 Gazdag G, Zsargó E, Vukov P, Ungvari GS, Tolna J. Change of medica student attitudes toward psychiatry: the impact of the psychiatric clerkship. Psychiatr Hung 2009; 24: 248-54.

37 Chung MC, Prasher VP. Differences in attitudes among medical students towards psychiatry in one English university. Psychol Rep 1995; 77: 843-7.

38 Sivakumar K, Wilkinson G, Toone BK, Greer S. Attitudes to psychiatry in doctors at the end of their 1st postgraduate year: 2-year follow-up of a cohort of medical students. Psychol Med 1986; 16: 457-60.

39 Clardy JA, Thrush CR, Guttenberger VT, Goodrich ML, Burton RPD. The junior-year psychiatric clerkship and medical students' interest in psychiatry. Acad Psychiatry 2000; 24: 35-40.

40 Niedermier JA, Bornstein R, Brandemihl A. The junior medical student psychiatry clerkship: curriculum, attitudes, and test performance. Acad Psychiatry 2006; 30: 136-43.

41 McParland M, Noble LM, Livingston G, McManus C. The effect of a psychiatric attachment on students' attitudes to and intention to pursue psychiatry as a career. Med Educ 2003; 37: 447-54.
42 Bobo WV, Nevin R, Greene E, Lacy TJ. The effect of psychiatric thirdyear rotation setting on academic performance, student attitudes, and specialty choice. Acad Psychiatry 2009; 33: 105-11.

43 Walters K, Raven P, Rosenthal J, Russell J, Humphrey C, Buszewicz M. Teaching undergraduate psychiatry in primary care: the impact on student learning and attitudes. Med Educ 2007; 41: 100-8.

44 Martin V, Bennett D, Pitale M. Medical students' perceptions of child psychiatry: pre- and post-psychiatry clerkship. Acad Psychiatry 2005; 29: 362-7.

45 Christison GW, Haviland MG. Requiring a one-week addiction treatment experience in a six-week psychiatry clerkship: effects on attitudes toward substance-abusing patients. Teach Learn Med 2003; 15: 93-7.

46 Silins E, Conigrave KM, Rakvin C, Dobbins T, Curry K. The influence of structured education and clinical experience on the attitudes of medical students towards substance misusers. Drug Alcohol Rev 2007; 26: 191200.

47 Landy J, Hynes J, Checinski K, Crome IB. Knowledge of and attitudes to substance misuse in undergraduate British medical students. Drug Educ Prev Polic 2005; 12: 137-48.

48 Oakley C, Oyebode F. Medical students' views about an undergraduate curriculum in psychiatry before and after clinical placements. BMC Med Educ 2008; 8: 26.

49 Lampe L, Coulston C, Walter G, Malhi G. Familiarity breeds respect: attitudes of medical students towards psychiatry following a clinical attachment. Australas Psychiatry 2010; 18: 348-53.

50 Korszun A Dinos S, Ahmed K, Bhui K. Student attitudes to menta illness: does medical school education reduce stigma? Acad Psychiatry 2011; 36: 197-204.

51 Lambert TW, Goldacre MJ, Davidson JM, Parkhouse J. Graduate status and age at entry to medical school as predictors of doctors' choice of long-term career. Med Educ 2001; 35: 450-4.

52 Rajagopal S, Rehil KS, Godfrey E. Psychiatry as a career choice compared with other specialties: a survey of medical students. Psychiatr Bull 2004; 28: 444-46.

53 Eagle PF, Marcos LR. Impact of the outpatient clerkship on medical students. Am J Psychiatry 1980; 137: 1599-602.

54 Feldmann TB. Medical students' attitudes toward psychiatry and mental disorders. Acad Psychiatry 2005; 29: 354-6.

55 Bashook PG, Weissman SH. Senior medical students' perceptions of the psychiatric clerkship. Am J Psychiatry 1982; 139: 1614-6.

56 Serby M, Schmeidler J, Smith J. Length of psychiatry clerkships - recent changes and the relationship to recruitment. Acad Psychiatry 2002; 26 $102-4$.

57 Christison GW, Haviland MG, Riggs ML. The medical condition regard scale: measuring reactions to diagnoses. Acad Med 2002; 77: 257-62.

58 Fabrega Jr H. Does a clerkship affect students' views of psychiatric patients? J Nerv Ment Dis 1995; 183: 736-42.

59 Angermeyer $M$, Matschinger $\mathrm{H}$. The effect of personal experience with mental illness on the attitude towards individuals suffering from mental disorders. Soc Psychiatry Psychiatr Epidemiol 1996; 31: 321-6.

60 Woloschuk W, Harasym PH, Temple W. Attitude change during medical school: a cohort study. Med Educ 2004; 38: 522-34.

61 Drinkwater J, Tully MP, Dornan T. The effect of gender on medica students' aspirations: a qualitative study. Med Educ 2008; 42: 420-6.

62 Cinnirella M, Loewenthal KM. Religious and ethnic group influences on beliefs about mental illness: a qualitative interview study. $\mathrm{Br} J$ Med Psychol 1999; 72: 505-24.

63 Bhui K. Culture, religion and health care. Int J Integr Care 2010; 10: 5759.

64 Balon R, Franchini GR, Freeman PS, Hassenfeld IN, Keshavan MS Yoder E. Medical students' attitudes and views of psychiatry: 15 years later. Acad Psychiatry 1999; 23: 30-6.

65 NHS Information Centre. Attitudes to Mental IIIness - 2011 Survey Report. NHS Information Centre, 2011. 
66 Griffith $\mathrm{CH}$, Wilson JF. The loss of student idealism in the 3rd-year clinical clerkships. Eval Health Prof 2001; 24: 61-71.

67 Hojat M, Vergare M, Maxwell K, Brainard G, Herrine S, Isenberg G, et al. The devil is in the third year: a longitudinal study of erosion of empathy in medical school. Acad Med 2009; 84: 1182-91.

68 Tsimtsiou Z, Kerasidou O, Efstathiou N, Papaharitou S, Hatzimouratidis K, Hatzichristou D. Medical students' attitudes toward patient-centred care: a longitudinal survey. Med Educ 2007; 41: 146-53.

69 Eron LD. The effect of medical education on attitudes: a follow-up study. J Med Educ 1958; 33: 25-33.

70 Calvert S, Sharpe M, Power M, Lawrie S. Does undergraduate education have an effect on Edinburgh medical students' attitudes to psychiatry and psychiatric patients? J Nerv Ment Dis 1999; 187: 757-61.

71 Cepoiu M, McCusker J, Cole MG, Sewitch M, Belzile E, Ciampi A. Recognition of depression by non-psychiatric physicians - a systematic literature review and meta-analysis. J Gen Intern Med 2008; 23: 25-36.
72 Arkar H, Eker D. Influence of a 3-week psychiatric training programme on attitudes toward mental illness in medical students. Soc Psychiatry Psychiatr Epidemiol 1997; 32: 171-6.

73 Inandi T, Aydin N, Turhan E, Gultekin D. Social distances of medical students from a person in a depression vignette; a cross-sectional study. TJPH 2009; 6: 19-28.

74 Reynolds WM. Development of reliable and valid short forms of the Marlowe-Crowne Social Desirability Scale. J Clin Psychol 1982; 38: 11925.

75 Wigney T, Parker G. Medical student observations on a career in psychiatry. Aust N Z J Psychiatry 2007; 41: 726-31.

76 Cutler JL, Harding KJ, Mozian SA, Wright LL, Pica AG, Masters SR, et al. Discrediting the notion 'working with "crazies" will make you "crazy"': addressing stigma and enhancing empathy in medical student education. Adv Health Sci Edu 2009; 14: 487-502.

77 Cutler JL, Alspector SL, Harding KJ, Wright LL, Graham MJ. Medical students' perceptions of psychiatry as a career choice. Acad Psychiatry 2006; 30: 144-9. 